\title{
Distinctions in the Management, Patient Impact, and Clinical Profiles of Pachyonychia Congenita Subtypes
}

\author{
Albert G. Wu ${ }^{a}$ Shari R. Lipner ${ }^{b}$ \\ ${ }^{a}$ New York Medical College, New York, NY, USA; ${ }^{b}$ Department of Dermatology, Weill Cornell Medicine, New York, NY, USA
}

\section{Keywords}

Pachyonychia congenita $\cdot$ Hypertrophic nail dystrophy .

Nail disease - Quality of life - Disease management .

Epidemiology $\cdot$ Genetic analysis

\begin{abstract}
Introduction: Pachyonychia congenita (PC) is a rare dermatosis that confers lifelong physical and emotional morbidities in affected patients. However, the clinical findings, treatments, and psychosocial impact of this disease have not been adequately described. The International PC Research Registry (IPCRR), a multinational initiative to collect data on PC patients, has allowed an opportunity to distinguish the salient features of this disease. We aimed to characterize the breadth and extent of nail disease, treatments, and quality of life in PC patients, and to describe any significant differences in clinical presentation or treatment of PC subtypes. Methods: The most recent IPCRR patient survey data consisting of an 857-response questionnaire and a 102-response addendum were analyzed in a retrospective analysis. The survey data were collected as part of a multinational, multicenter initiative and comprise the largest representative population of PC to date. Participants (survey
\end{abstract}

respondents) were included in the study based on questionnaire responses and a genetic confirmation of having a PC subtype. Results: A total of 857 survey responses were collected. Genetic variations among PC subtypes influence nail disease onset and severity of symptoms. Nail disease negatively impacts patients' emotional health, especially during the adolescent and young adult years. Nail treatment tools vary little in terms of effectiveness and acquired infection rates. Conclusion and Discussion: Patients with different PC subtypes have distinct clinical nail presentations and psychosocial impact. Genetic testing should be used to confirm $\mathrm{PC}$ diagnoses. Further characterization of $\mathrm{PC}$, especially the rarer subtypes, may allow for more individualized patient education.

(C) 2021 The Author(s) Published by S. Karger AG, Basel

\section{Introduction}

Pachyonychia congenita (PC) is an autosomal dominant dermatosis due to heterozygous mutations in 5 possible keratin genes [1]. Clinical findings include hypertrophic nail dystrophy, palmoplantar hyperkeratosis [2], pilosebaceous cysts, steatocystomas, neuropathic pains [3,

\begin{tabular}{ll}
\hline karger@karger.com & $\begin{array}{l}\text { C } 2021 \text { The Author(s) } \\
\text { Published by S. Karger AG, Basel }\end{array}$ \\
www.karger.com/sad & $\begin{array}{l}\text { This is an Open Access article licensed under the Creative Commons } \\
\text { Attribution-NonCommercial-4.0 International License (CC BY-NC) } \\
\text { (http://www.karger.com/Services/OpenAccessLicense), applicable to } \\
\text { the online version of the article only. Usage and distribution for com- } \\
\text { mercial purposes requires written permission. }\end{array}$ \\
BOPEN ACCESS &
\end{tabular}


4], dental defects $[5,6]$, and oral leukokeratosis $[7,8]$. Palmoplantar keratoderma is often severe and is the most debilitating problem for these patients. Hypertrophic nail dystrophy, defined as thickened and discolored fingernails and toenails, is another common clinical feature of PC $[9,10]$ with a negative impact on quality of life $[11,12]$ due to severe pain and susceptibility to infection. Quality of life is further influenced by the age of onset and severity of the dystrophy, which varies based on the genetic mutation and environment [13]. As a result, PC may present with a large spectrum of clinical profiles and nonclassic symptoms [14], even with mutations of the same gene [15-17]. Although current therapeutic options may provide some relief, none are able to adequately cure all cases [18], and most treatments are centered on pain control $[19,20]$. Surgical treatments such as nail removal may be beneficial [21], but may not be acceptable to many patients.

While PC has been historically subdivided into 4 subtypes (the most common being PC-1 and PC-2) based on genetic mutation, presence of additional symptoms [22, 23 ], timing of symptom onset $[24,25]$, and improved diagnosis have expanded the disease into 5 subtypes: PCK16, PC-K17, PC-K6a, PC-K6b, and PC-K6c based on genetic mutations $[24,26]$. Utilization of genetic sequencing has allowed for insights into the pathophysiology of the disease $[27,28]$ and variations depending on the subtype $[29,30]$ and nature of mutations. Multiple cellular processes have been implicated, including accumulation of autolysosomes [31], faulty regulation of expression [32-35], and altered epithelium cell composition. Case reports and cross-sectional analyses have highlighted clinical differences between these subtypes [1], such as an earlier onset of more extensive symptoms in PC-K6a [3639]. Genetic differences that translate into phenotypic variations are important for predicting the scope and severity of symptoms in PC patients.

Criteria for diagnosis of PC include a triad of toenail thickening, plantar keratoderma, and plantar pain $[9,11]$, but genetic testing is important for diagnostic confirmation, subtype classification [40,41], and ruling out other disorders $[23,24]$. The exact prevalence of PC is unknown, with estimates of 7,000-10,000 cases worldwide [40] or about 0.9 cases per million people [7]. Novel causative genes $[42,43]$ and affected populations $[44,45]$ are added frequently, but because of the rarity of the disease, there are limited data characterizing clinical and psychosocial aspects of the condition. The International PC Research Registry (IPCRR) is a multinational initiative to collect data on PC patients to guide research and treat-
Table 1. Demographics of survey respondents

\begin{tabular}{lc}
\hline Demographic & Proportion \\
\hline Sex, $n(\%)$ & \\
Male & $406 / 857(47)$ \\
Female & $451 / 857(52)$ \\
Age when survey was filled out, $n(\%)$ & \\
$1-4$ & $73(8.5)$ \\
$5-9$ & $78(9.1)$ \\
$10-14$ & $44(5.1)$ \\
$15-19$ & $45(5.2)$ \\
$20-24$ & $68(7.9)$ \\
$25-29$ & $65(7.5)$ \\
$30-40$ & $164(19.1)$ \\
$41-50$ & $98(11.4)$ \\
$51-60$ & $86(10)$ \\
$>60$ & $77(8.9)$ \\
Not disclosed & $59(6.8)$ \\
\hline Total & 857 \\
\hline
\end{tabular}

ment. In this study, using data compiled from 857 individuals with PC from the IPCRR, we distinguish salient nail findings of PC subtypes including the prevalence of common symptoms and examine the mental and physical impact of living with this disease.

\section{Materials and Methods}

The questionnaires and data were provided by IPCRR through the Pachyonychia Congenita Project (www.pachyonychia.org). The IPCRR questionnaires and the study were approved by Western Institutional Review Board (WIRB Study number 1057496; protocol number 20040468). Patient responses completed from April 2004 January 2019, consisting of 857 responses to the questionnaire and 102 responses to the addendum, were analyzed. As the PC project is the largest database of PC data, and PC is an extremely rare disease with an unknown incidence and prevalence, we considered the data set to be a fairly representative sample. Thickened nail numbers, age of onset, treatment methods, and infection rates were extracted from the original questionnaire, while nail color and questions pertaining to the psychological impact of PC were retrieved from the addendum. Responses were aggregated in Microsoft Excel. Sample standard deviation was used for separate fingernail and toenail calculations to account for the larger variation, while population standard deviation was used for combined fingernail and toenail calculations. All statistical analysis was performed using Excel Analysis Toolpak. Datasets related to this article, including the most recent data, can be found through contacting the pachyonychia congenita Project. This study conforms to the Strengthening the Reporting of Observational Studies in Epidemiology (STROBE) reporting guidelines as well as the Reporting of studies Conducted using Observational Routinely-collected health Data (RECORD) checklist. 
Table 2. Gene frequency for variants of PC

\begin{tabular}{llll}
\hline Gene & Protein & Phenotypes & $\begin{array}{l}\text { Proportion of PC } \\
\text { patients }\end{array}$ \\
\hline K16 & Type 1 Keratin & PC-K16, PC Type 1 (Jadassohn-Lewandowsky), ${ }^{*}$ PC Type 4 (PC Tarda)* & 264/857 (30.8\%) \\
K17 & Type 1 Keratin & PC-K17, PC Type 2 (Jackson-Lawler), ${ }^{*}$ PC Type 4 (PC Tarda)* & $138 / 857(16.1 \%)$ \\
K6a & Type 2 Keratin & PC-K6a, PC Type 1 (Jadassohn-Lewandowsky)* & $352 / 857(41 \%)$ \\
K6b & Type 2 Keratin & PC-K6b, PC Type 2 (Jackson-Lawler)* & $76 / 857(8.8 \%)$ \\
K6c & Type 2 Keratin & PC-K6c, Palmoplantar keratoderma* & $27 / 857(3 \%)$ \\
\hline
\end{tabular}

PC, pachyonychia congenita. * Historical or original forms of classification.

\section{Results}

Survey responses were fairly evenly distributed by sex and age, with $47 \%$ of respondents male and $52 \%$ of respondents female (Table 1). The frequency of each PC phenotype was calculated, with the most common PCK6a, followed by PC-K16, PC-K17, and PCK-6b, and the least common PC-K6c (Table 2).

The number of thickened fingernails and toenails and age of thickening onset were analyzed by genetic mutation (Table 3). The overall proportion of patients who reported thickened fingernails was 648/857 (75.6\%), while the proportion of reported thickened toenails was $825 / 857$ (96.2\%). Of the PC mutations, K6a was associated with both the highest average number of thickened fingernails and toenails (9.2 and 9.5, respectively) and a significant proportion $(306 / 435)$ of patients with thickened nails within the first year of life. Mutations in K6c corresponded with the lowest average number of fingernails and toenails thickened ( 0.07 and 2, respectively). For gene defects in both K6a and K17, over 73\% of patients experienced fingernail or toenail thickening within a year of life. PC resulting from mutations in K16 or K6b had a more normal distribution, with the majority of thickening onset occurring between the ages of 1 and 9 years. By age 10 years, $83 \%$ of PC patients had experienced fingernail or toenail thickening.

Nail plate discoloration was reported in 71/102 (69\%) of PC patients (Table 3). Yellow made up the largest proportion of toenail discolorations (44\%) as well as the largest proportion of overall nail discolorations (41\%). Brown/tan was the most common fingernail discoloration (40\%) and second most common overall nail discoloration (38\%). The remaining spectrum of colors including green, gray, dark, or black was rare, with reported cases making up a smaller proportion than a normal or unaffected nail.
To further examine the emotional impact of PC symptoms, we organized the responses to a series of questions pertaining to emotions experienced by patients who had thickened nails. The questions specifically asked if and when patients felt "bothered," "self-conscious," or "embarrassed" by the appearance of their nails. After tabulating responses to these questions independently, they were grouped into one supergroup named "Emotional Distress" (Table 4) to increase statistical strength and to more effectively discern any negative emotional impact. The highest proportion of responses of "Never" Distressed (indicating never felt bothered, embarrassed, or self-conscious) occurred between the ages of 1 and 5, dropping sharply after that period while the highest proportions of "Always" and "Often/Frequently" Distressed rose steadily, peaking between the ages of 11 and 20.

While mutations in K6a were associated with more extensive and earlier onset of symptoms, they were not associated with the highest proportion of patients who were "Always" distressed; in fact, the distribution was fairly evenly split (Table 4). Importantly, patient distress seemed independent of the severity of symptoms indicated by the PC subtype (Table 4). The absence of a standardized maintenance protocol for thickened nails was evident in the large variation of survey responses, with over 35 unique treatments reported in the survey (Table 5). The most common methods to manage thickened fingernails and toenails were clippers only (56/683), clippers and razors (35/683), clippers and razors and sanders (30/683), and razors only (25/683).

To analyze efficacy of different therapeutic modalities, we included only treatments with at least 30 responses to attain sufficient statistical strength for adequate analysis. The analyses drew from questions pertaining to frequency of infections as well as the impact of thickened nails on patients' daily lives and activities. The rate of frequent nail infections $(1+$ infection per week) was calculated, and the 
Table 3. Thickened nail statistics

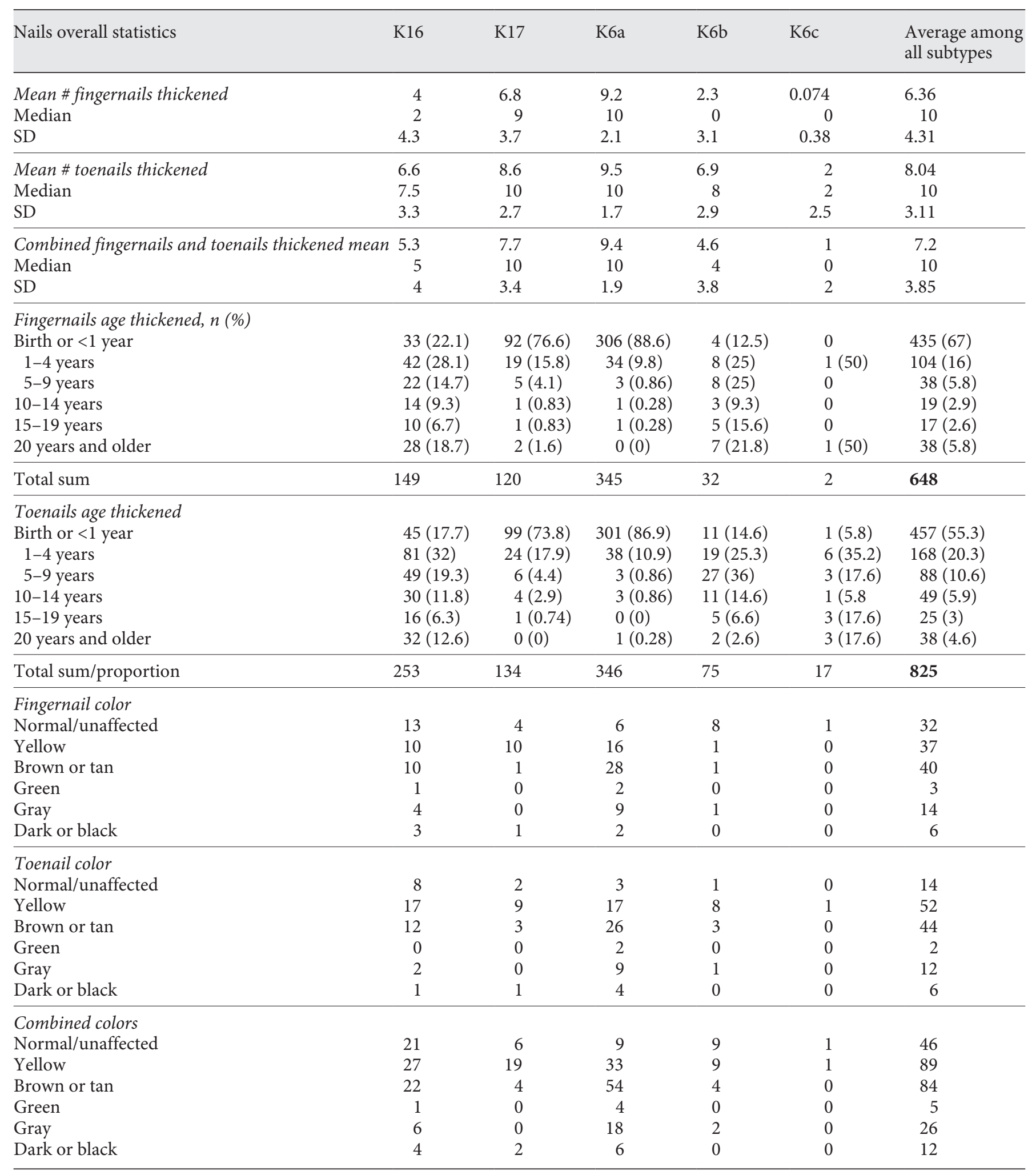

Novel Distinctions in the Profile and Management of PC Nail Disease 
treatments with the lowest frequent infection rates (fingernail or toenail) were as follows: razor and clipper ( $0 \%)$, scalpel and clipper $(0 \%)$, sanders only $(0 \%)$, razors and sanders and clippers (1.7\%), and sanders and clippers (2.7\%). The treatment methods with the highest proportion of frequent infections were razor and pumice stone and clipper (8.3\%), clippers only (7.8\%), and razors only (5.8\%). To clarify potential relationships between individual tools and infection rates, the frequent infection rate for each individual tool was calculated (Table 5). There were no clear statistical outliers, with all tools having a $2-3.5 \%$ infection rate.

To quantify the infection rate and emotional impact on PC patients with treatment type, 2 weighted scores were used: Overall infection rate (OIR) and daily life impact (DLI) with point values assigned for each response. For OIR, 5 points were assigned for frequent, 3 points for sometimes, 2 points for seldom, and 1 point for never. For DLI, 4 points were assigned for always, 2 points for sometimes, and 1 point for never.

After averaging the total points for each tool utilized, we calculated the measures of central tendency. The mean OIR was 1.82 (standard deviation 0.15). The highest score among the sample was for "clippers only" (2.09), while the lowest score was for "sanders only" (1.64). Of note, one treatment combination, "razors, scalpel, pumice stone, sanders, and clippers," was not included in the measures of central tendency calculations due to missing the sample cutoff $(n=29)$, but was $>2$ standard deviations above the mean $(\mathrm{OIR}=2.14)$.

Regarding the DLI, the average score was 2.57 (standard deviation 0.24 ). The highest score within the sample was "razor, pumice stone, and clippers" (2.84), indicating a greater positive emotional impact on the patient's daily life, while the lowest score was for "sanders only" (2.175). The combination of "razors, scalpel, pumice stone, sanders, and clippers" was an outlier, with a very high DLI score of 3.69 .

\section{Discussion/Conclusion}

$\mathrm{PC}$ is a rare, autosomal dominant condition which has been historically diagnosed using clinical criteria $[39,46]$. Confirmation of diagnoses by genetic testing [47] and the establishment of the IPCRR have allowed for a more scientific and accurate classification [48] into distinct subtypes. Using a self-reported patient survey of PC patients,

Table 4. Gene and age and psychological impact on life

\begin{tabular}{lrlllr}
\hline $\begin{array}{l}\text { Gene and } \\
\text { emotional distress }\end{array}$ & K16 & K17 & K6a & K6b & K6c \\
\hline $\begin{array}{l}\text { Always } \\
\text { Often/frequently }\end{array}$ & 53 & 55 & 163 & 18 & 0 \\
$\begin{array}{l}\text { Sometimes } \\
\text { Never }\end{array}$ & 87 & 44 & 123 & 30 & 0 \\
\hline Age and & 160 & 42 & 147 & 54 & 6 \\
emotional distress & Always & Often/ & Some- & Never & N/A \\
\hline $1-5$ & & frequently & times & & \\
6-10 & 24 & 17 & 42 & 205 & 18 \\
$11-20$ & 55 & 56 & 74 & 88 & 33 \\
$20-30$ & 90 & 86 & 43 & 42 & 45 \\
$31+$ & 74 & 66 & 62 & 32 & 72 \\
& 46 & 47 & 63 & 42 & 108 \\
\hline
\end{tabular}

Table 5. Treatment effectiveness on thickened nail dystrophy

\begin{tabular}{|c|c|c|c|c|c|c|c|c|}
\hline \multicolumn{9}{|c|}{ Effectiveness of nail dystrophy maintenance by tool } \\
\hline Rate of frequent infections, $n(\%)$ & $9 / 114(7.8)$ & $3 / 51(5.8)$ & $0 / 71(0)$ & $4 / 48(8.3)$ & $1 / 57(1.7)$ & $0 / 39(0)$ & $1 / 37(2.7)$ & $0 / 40(0 \%)$ \\
\hline Overall infection score & 2.09 & 1.8 & 1.8 & 1.97 & 1.78 & 1.64 & 1.83 & 1.65 \\
\hline DLI score & 2.41 & 2.65 & 2.74 & 2.84 & 2.86 & 2.17 & 2.42 & 2.46 \\
\hline $\begin{array}{l}\text { Frequent infection rate by tool } \\
\text { Frequent infection rate, } n(\%)\end{array}$ & $18 / 541(3.3)$ & $6 / 213(2.8)$ & $6 / 236(2.5)$ & $9 / 377(2.3)$ & $5 / 159(3.1)$ & & & \\
\hline
\end{tabular}

DLI, daily life impact. 
we examined several nail related aspects of PC under the genetic classifications.

Our data confirmed the previous reports of gene-specific disease courses in PC, specifically PC-K6a having an earlier onset and more severe nail symptoms [49] and PC-K6c expressing milder clinical manifestations than other gene defects $[49,50]$. The data also corroborated earlier genotype-phenotype correlations regarding K16 mutations [50,51], with this mutation being associated with higher numbers of fingernails and toenails affected, earlier age of onset, and a relatively high degree of variation of symptoms. Similar genotype-phenotype associations are also found in K17 mutation cases [49]. Continuously validating the literature is crucial for maintaining an accurate clinical profile of PC to effectively care for patients.

We also made novel observations regarding differences between PC subtypes. PC-K17 and PC-K6a appear to have earlier onset of nail disease than the other subtypes, with the majority of patients having symptoms within the first year of life. Subtypes PC-K16 and PC-K6b appear to have the largest range of nail symptoms, with some patients having minimal impact on their lives, while for others it significantly affects their daily routines. Previous studies have shown a genotype-phenotype correlation between certain mutations of K16 and severity of PC, with the p.Asn125Asp and p.Arg127 mutations being associated with more severe symptoms than the p.Asn125Ser and p.Arg127Cys mutations $[52,53]$. This mutation variation may help to explain heterogeneity of these observations.

Understanding the differences between PC subtypes may help to individualize treatments and help patients better understand their disease course. Genetic analyses have begun to unravel mutation-specific patterns of expression [54] and identified mutations which contribute to distinct physiological symptoms of PC, such as tooth decay [5] and mitochondrial dysfunction [31, 55]. As such, it may be more practical for future studies to focus on discerning the disease course and pathology of a single subtype.

With regards to the physical and psychological impact of PC, our study underscores the negative experiences patients suffer due to their nail condition. Since there are large variations in the number of nails involved, ages of presentation, and nail discolorations, treatment should be individualized. In terms of nail discolorations, the nail color may indicate a secondary nail condition such as onychomycosis (yellow/brown), pseudomonas nail infection (green), or subungual hematoma (dark/brown/

Novel Distinctions in the Profile and Management of PC Nail Disease black). Nail clippings with histopathology, bacterial cultures, and fungal cultures may be used to diagnose other secondary nail conditions that may be contributing to the discoloration and symptoms, with appropriate treatment prescribed to alleviate these signs and symptoms $[56,57]$. Over half of patients reported at least some psychological distress across the different gene groups, and most patients reported negative experiences during childhood and adolescence. We hypothesize that while the majority of nail thickening occurs within the first year of life, these patients have not begun to associate their physical features with any negative societal experiences. Previous studies have reported that most children and adolescents with PC experience difficulties with various activities at school [58] as well as limitations in wearing clothes and playing sports [59]. Therefore, dermatologists and other physicians must learn how to effectively manage the plantar hyperkeratosis, nail thickening, and nail discoloration which may help with both physical and psychosocial symptoms. We also recommend a multifaceted approach with referral to the PC project, where patients can have access to other PC patients through patient advocacy programs, private social media forums and patient support meetings. Group therapy or counseling sessions may help to empower patients to speak about their condition and experiences. Referral to a psychiatrist may be considered in select cases.

Many treatments for PC, such as Botox injections [60, 61], focus on pain management. Although some research has focused on treatment of the underlying cause, such as reducing expression of keratin alleles $[62,63]$, success has only been reported in small group case reports. Therefore, for most patients, self-management of symptoms becomes the norm. Although an enormous variety of tools are employed by patients to treat dystrophic nails, no single method has shown a significant advantage over another: infection rates and impact on daily activities remain similar across combinations of tools. It is important for physicians to preemptively address symptom management since $71.2 \%$ of PC patients with nail infections never sought treatment [59]. For patients with severe nail disease, such as those who experience recurrent infections or unrelenting pain despite conservative methods, nail removal may be considered. Although only a small proportion of PC patients opt for nail avulsion, the majority of patients who have undergone this procedure report positive outcomes and would recommend the procedure to others [21]. Use of keratolytics, including $40 \%$ urea to remove dystrophic nails, has limited efficacy [64, 65]. Early exposure to nail maintenance tools and appro- 
priate education may help increase familiarity and improve efficacy. Thus, we recommend that patient comfort and preference prioritized when recommending individual methods for nail maintenance.

This study was limited by its retrospective method of data collection and small sample size for rarer subtypes of PC. Some survey questions required patients to list or recall experiences beginning from their birth, which may be difficult to detail. Despite the large overall sample size, PC subtype K6c was still underrepresented, making up only $3 \%$ of survey respondents; therefore, it was difficult to draw strong correlations from the data.

PC subtypes show distinct differences in nail disease onset and course, which allows physicians to provide more individualized education and treatment, and early referral to patient advocacy through the PC project. Despite the clinical viability of the new PC classifications, there remains a large variation in nail symptoms within some subtypes. Additional clinical and genetic analyses are needed to further subdivide each PC subtype, with the goal of individualizing treatment regimens for each patient.

\section{Acknowledgement}

We are grateful to the Pachyonychia Congenita Project for the data and support on the project. We are indebted to all the patients with PC who participated in the IPCRR.

\section{Statement of Ethics}

The IPCRR questionnaires and the study were approved by Western Institutional Review Board (WIRB Study number 1057496; protocol number 20040468).

This study conforms to the Strengthening the Reporting of Observational Studies in Epidemiology (STROBE) reporting guidelines as well as the Reporting of studies Conducted using Observational Routinely-collected health Data (RECORD) checklist.

\section{Conflict of Interest Statement}

Dr. Lipner and Mr. Wu have no conflicts of interest, relevant financial activities, or relationships which could be perceived to have influenced, or that give the appearance of potentially influencing, what is written in the submitted work, to disclose.

\section{Funding Sources}

There was no funding for this study.

\section{Author Contributions}

Dr. Lipner and Mr. Wu had full access to all the data in the study and take responsibility for the integrity of the data and the accuracy of the data analysis. Study concept and design: Lipner. Acquisition of data: Lipner and Wu. Analysis and interpretation of data: Lipner and Wu. Drafting of the manuscript: Wu. Critical revision of the manuscript for important intellectual content: Lipner. Statistical analysis: Lipner, Wu. Study supervision: Lipner.

\section{References}

1 Cammarata-Scalisi F, Natsuga K, Toyonaga E, Nishie W, Shimizu H, Avendaño A, et al. Early severe pachyonychia congenita subtype PC-K6a with a novel mutation in the KRT6A gene. J Eur Acad Dermatol Venereol. 2017 Feb;31(2):e94-6.

2 Sabogal Gómez MV, González V, Martín JM. Facial cystic lesions and onychodystrophy. Pediatr Dermatol. 2018 Jul;35(4):517-8.

3 Brill S, Sprecher E, Smith FJD, Geva N, Gruener $\mathrm{H}$, Nahman-Averbuch $\mathrm{H}$, et al. Chronic pain in pachyonychia congenita: evidence for neuropathic origin. Br J Dermatol. 2018; 179(1):154-62.

4 Rittié L, Kaspar RL, Sprecher E, Smith FJD. Report of the 13th Annual International Pachyonychia congenita consortium symposium. Br J Dermatol. 2017 May;176(5):1144-7.

5 Duverger O, Carlson JC, Karacz CM, Schwartz ME, Cross MA, Marazita ML, et al. Genetic variants in pachyonychia congenita-associated keratins increase susceptibility to tooth decay. PLoS Genet. 2018 Jan 22 [cited 2019 Jul 23];14(1):e1007168.
6 Duverger O, Cross MA, Smith FJD, Morasso MI. Enamel anomalies in a pachyonychia congenita patient with a mutation in KRT16. J Invest Dermatol. 2019 Jan 1;139(1):238-41.

7 Pinna R, Cocco F, Campus G, Conti G, Milia E, Sardella A, et al. Genetic and developmental disorders of the oral mucosa: epidemiology; molecular mechanisms; diagnostic criteria; management [Internet]. Periodontology 2000. 2019 [cited 2019 Jul 19];80(1):12-27. http: //onlinelibrary.wiley.com/doi/abs/ 10.1111/prd.12261.

8 Nico MM, Hammerschmidt M, Lourenço SV. Oral mucosal manifestations in some genodermatoses: correlation with cutaneous lesions. Eur J Dermatol. 2013 Sep;23(5):581-91.

9 Smith FJ, Hansen CD, Hull PR, Kaspar RL, McLean WI, O’Toole E, et al. Pachyonychia congenita. In: Adam MP, Ardinger $\mathrm{HH}$, Pagon RA, Wallace SE, Bean LJ, Stephens K, et al. et al., editors. GeneReviews ${ }^{\oplus}$ [Internet]. Seattle (WA): University of Washington, Seattle; 1993 [cited 2019 Jul 2]. http://www.ncbi. nlm.nih.gov/books/NBK1280/.
10 What is pachyonychia congenita? [Internet]. [cited 2019 Jul 2]. Available from: https:// www.pachyonychia.org/what-is-pc/.

11 Wallis T, Poole CD, Hoggart B. Can skin disease cause neuropathic pain? A study in pachyonychia congenita. Clin Exp Dermatol. 2016 Jan;41(1):26-33.

12 Pan B, Byrnes K, Schwartz M, Hansen CD, Campbell CM, Krupiczojc M, et al. Peripheral neuropathic changes in pachyonychia congenita: pain. 2016 Dec;157(12):2843-53.

13 Lovgren ML, McAleer MA, Irvine AD, Wilson NJ, Tavadia S, Schwartz ME, et al. Mutations in desmoglein 1 cause diverse inherited palmoplantar keratoderma phenotypes: implications for genetic screening. Br J Dermatol. 2017 May;176(5):1345-50.

14 O'Kane AM, Jackson CP, Mahadevan M, Barber C. Laryngeal manifestations of pachyonychia congenita: a clinical case and discussion on management for the otolaryngologist. J Laryngol Otol. 2017 Jul;131(S2):S53-6. 
15 Zamiri M, Wilson NJ, O'Toole EA, Smith FJD. Novel mutations in desmoglein 1: focal palmoplantar keratoderma in milder phenotypes. Br J Dermatol. 2019 Sep;181(3):618-20.

16 Smith FJD, Kreuser-Genis IM, Jury CS, Wilson NJ, Terron-Kwiatowski A, Zamiri M. Novel and recurrent mutations in keratin 1 cause epidermolytic ichthyosis and palmoplantar keratoderma. Clin Exp Dermatol. 2019 Jul;44(5):528-34.

17 Wilson NJ, Leachman SA, Hansen CD, McMullan AC, Milstone LM, Schwartz ME, et al. A large mutational study in pachyonychia congenita. J Invest Dermatol. 2011 May 1; 131(5):1018-24.

18 Goldberg I, Fruchter D, Meilick A, Schwartz ME, Sprecher E. Best treatment practices for pachyonychia congenita. J Eur Acad Dermatol Venereol. 2014;28(3):279-85.

19 Koren A, Sprecher E, Reider E, Artzi O. A treatment protocol for botulinum toxin injections in the treatment of pachyonychia congenita-associated keratoderma. Br J Dermatol [Internet]. 2019 Sep 8 [cited 2019 Oct 18]. https: //onlinelibrary.wiley.com/doi/abs/ 10.1111/bjd.18169.

20 Grando SA, Zachary CB. The non-neuronal and nonmuscular effects of botulinum toxin: an opportunity for a deadly molecule to treat disease in the skin and beyond. Br J Dermatol. 2018 May;178(5):1011-9.

21 DeKlotz CMC, Schwartz ME, Milstone LM. Nail removal in pachyonychia congenita: patient-reported survey outcomes. J Am Acad Dermatol. 2017 May 1;76(5):990-2.

22 Ward KM, Cook-Bolden FE, Christiano AM, Çelebi JT. Identification of a recurrent mutation in keratin $6 \mathrm{a}$ in a patient with overlapping clinical features of pachyonychia congenita types 1 and 2. Clin Exp Dermatol. 2003; 28(4):434-6.

23 Smith FJ, Liao H, Cassidy AJ, Stewart A, Hamill KJ, Wood P, et al. The genetic basis of pachyonychia congenita. J Investig Dermatol Symp Proc. 2005 Oct;10(1):21-30.

24 Agarwala MK, Schwartz ME, Smith FJ. Pachyonychia congenita: new classification and diagnosis. Indian J Dermatol. 2016;61(5):567.

25 Rathore PK, Khullar V, Das A. Pachyonychia congenita type 1: case report and review of the literature. Indian J Dermatol. 2016;61(2): 196-9.

26 McLean WH, Hansen CD, Eliason MJ, Smith FJ. The phenotypic and molecular genetic features of pachyonychia congenita. J Invest Dermatol. 2011 May 1;131(5):1015-7.

27 Leube RE, Schwarz N. Sex matters: interfering with the oxidative stress response in pachyonychia congenita. J Invest Dermatol. 2018 May;138(5):1019-22.

28 Kerns ML, Hakim JMC, Zieman A, Lu RG, Coulombe PA. Sexual dimorphism in response to an NRF2 inducer in a model for pachyonychia congenita. J Invest Dermatol. 2018 May;138(5):1094-100.

29 Hobbs RP, DePianto DJ, Jacob JT, Han MC, Chung BM, Batazzi AS, et al. Keratin-depen- dent regulation of Aire and gene expression in skin tumor keratinocytes. Nat Genet. 2015 Aug;47(8):933-8.

30 Escobar-Hoyos LF, Shah R, Roa-Peña L, Vanner EA, Najafian N, Banach A, et al. Keratin-17 promotes p27KIP1 nuclear export and degradation and offers potential prognostic utility. Cancer Res. 2015 Sep 1;75(17):365062.

31 Lehmann SM, Leube RE, Schwarz N. Keratin 6a mutations lead to impaired mitochondrial quality control. Br J Dermatol [Internet]. 2020 Mar [cited 2019 Jul 23];182(3):636-47. https: //onlinelibrary.wiley.com/doi/abs/ 10.1111/bjd.18014.

32 Harmon RM, Simpson CL, Johnson JL, Koetsier JL, Dubash AD, Najor NA, et al. Desmoglein-1/Erbin interaction suppresses ERK activation to support epidermal differentiation. J Clin Invest. 2013 Apr 1;123(4):1556-70.

33 Krupiczojc MA, O’Toole EA. Plantar pain in pachyonychia congenita. Br J Dermatol. 2018 Jul;179(1):11-2.

34 Zieman AG, Coulombe PA. Pathophysiology of pachyonychia congenita-associated palmoplantar keratoderma: new insights into skin epithelial homeostasis and avenues for treatment. Br J Dermatol [Internet]. 2019 Jul 24 [cited 2019 Oct 18]. https://onlinelibrary. wiley.com/doi/abs/10.1111/bjd.18033.

35 Spaunhurst KM, Hogendorf AM, Smith FJ, Lingala B, Schwartz ME, Cywinska-Bernas A, et al. Pachyonychia congenita patients with mutations in KRT6A have more extensive disease compared with patients who have mutations in KRT16. Br J Dermatol. 2012;166(4): 875-8.

36 Gruber R, Wilson NJ, Smith FJ, Grabher D, Steinwender L, Fritsch PO, et al. Increased pachyonychia congenita severity in patients with concurrent keratin and filaggrin mutations. Br J Dermatol. 2009 Dec;161(6):1391-5.

37 Zhou HL, Yang S, Gao M, Zhao XY, Zhu YG, $\mathrm{Li}$ W, et al. A novel missense mutation L468Q of keratin $6 \mathrm{a}$ in pachyonychia congenita type 1. J Eur Acad Dermatol Venereol. 2007;21(3): 351-5.

38 Eliason MJ, Leachman SA, Feng BJ, Schwartz $\mathrm{ME}$, Hansen CD. A review of the clinical phenotype of 254 patients with genetically confirmed pachyonychia congenita. J Am Acad Dermatol. 2012 Oct 1;67(4):680-6.

39 Smith FJD, McLean WHI. Keratin 6b variant p.Gly499Ser reported in delayed-onset pachyonychia congenita is a non-pathogenic polymorphism. J Dermatol. 2017 Dec;44(12): e312.

40 Guo K, Xiao S, Geng S, Feng Y, Zhang D, Zhou P, et al. Delayed-onset pachyonychia congenita caused by a novel mutation in the V2 domain of keratin 6b. J Dermatol. 2014; 41(1):108-9.

41 Jiráková $\mathrm{A}$, Rajská $\mathrm{L}$, Rob $\mathrm{F}$, Džambová $\mathrm{M}$, Sečníková Z, Göpfertová D, et al. First case of pachyonychia congenita in the Czech Republic: keratinizing disorder, pachyonychia congenita. Dermatol Ther. 2015 Jan;28(1):10-2.
42 Ghazawi FM, Hassani-Ardakani K, Henriques $\mathrm{L}$, Jafarian $\mathrm{F}$. Identification of a novel substitution mutation (R103C) in the rod domain of the keratin 17 gene associated with pachyonychia congenita type 2 . Int J Dermatol. 2019 Feb;58(2):233-6.

43 Chiriac A, Rusu C, Murgu A, Chiriac AE, Wilson NJ, Smith FJD. First report of Pachyonychia congenita type PC-K6a in the romanian population. p. 4.

44 Xu Q, Zhang Q, Tang L, Jin L, Wang X, Kan $\mathrm{L}$, et al. A KRT16 mutation in the first Chinese pedigree with Pachyonychia congenita and review of the literatures. J Cosmet Dermatol [Internet]. 2019 Mar 12 [cited 2019 Oct 18]. http://doi.wiley.com/10.1111/jocd.12905.

45 Terrinoni A, Smith FJ, Didona B, Canzona F, Paradisi M, Huber M, et al. Novel and recurrent mutations in the genes encoding keratins $\mathrm{K} 6 \mathrm{a}, \mathrm{K} 16$ and $\mathrm{K} 17$ in 13 cases of pachyonychia congenita. J Invest Dermatol. 2001 Dec 1; 117(6):1391-6.

46 Leachman SA, Kaspar RL, Fleckman P, Florell SR, Smith FJ, McLean WH, et al. Clinical and pathological features of pachyonychia congenita. J Investig Dermatol Symp Proc. 2005 Oct 1;10(1):3-17.

47 Tatiane A, Slape D, Lawless R, Frew JW. A systematic review of reported cases of pachyonychia congenita tarda. Clin Exp Dermatol. 2019 Aug;44(6):606-12

48 Wilson NJ, O’Toole EA, Milstone LM, Hansen CD, Shepherd AA, Al-Asadi E, et al. The molecular genetic analysis of the expanding pachyonychia congenita case collection. Br J Dermatol. 2014 Aug;171(2):343-55.

49 Wee JS, Smith FJ, Wilson NJ, O’Toole EA. Focal PPK secondary to a novel KRT6C mutation (Pachyonychia congenita-K6c). J Eur Acad Dermatol Venereol. 2016;30(8):1415-6.

$50 \mathrm{Fu} \mathrm{T}$, Leachman SA, Wilson NJ, Smith FJ, Schwartz ME, Tang JY. Genotype-phenotype correlations among pachyonychia congenita patients with K16 mutations. J Invest Dermatol. 2011 May;131(5):1025-8.

51 Vodo D, O’Toole EA, Malchin N, Lahav A, Adir N, Sarig O, et al. Striate palmoplantar keratoderma resulting from a missense mutation in DSG1. Br J Dermatol. 2018 Sep;179(3): 755-7.

52 Lipner SR, Scher RK. Onychomycosis: clinical overview and diagnosis. J Am Acad Dermatol. 2019 Apr 1;80(4):835-51.

53 Cao YA, Hickerson RP, Seegmiller BL, Grapov D, Gross MM, Bessette MR, et al. Gene expression profiling in pachyonychia congenita skin. J Dermatol Sci. 2015 Mar; 77(3):156-65.

54 Dabbagh B, Cukier O, Yeganeh M, Halal F, dos Santos BF. Pachyonychia congenita associated with a novel variant of KRT17 presenting unusual oral manifestations [internet]. 2019 [cited 2019 Jul 23]. Available from: https: //www.ingentaconnect.com/content/ aapd/jodc/2019/00000086/00000001/art0000 $9 \% 3$ bjsessionid $=1 \mathrm{mq} 8 \mathrm{dbgaaeqm} 9 . \mathrm{x}$-ic live-01.
Novel Distinctions in the Profile and Management of PC Nail Disease
Skin Appendage Disord 2021;7:194-202 DOI: $10.1159 / 000513340$ 
55 Lipner SR, Scher RK. Onychomycosis: treatment and prevention of recurrence. J Am Acad Dermatol. 2019 Apr 1;80(4):853-67.

56 Agarwala M, Salphale P, Peter D, Wilson NJ, Pulimood S, Schwartz ME, et al. Keratin 17 mutations in four families from India with Pachyonychia congenita. Indian J Dermatol. 2017;62(4):422-6.

57 Tariq S, Schmitz ML, Kanjia MK. Chronic foot pain due to pachyonychia congenita in a pediatric patient: a successful management strategy. A A Case Rep. 2016 May;6(10):3057.

58 Shah S, Boen M, Kenner-Bell B, Schwartz M, Rademaker A, Paller AS. Pachyonychia congenita in pediatric patients: natural history, features, and impact. JAMA Dermatol. 2014 Feb 1;150(2):146-53.
59 Campanati A, Martina E, Giuliodori K, Consales V, Bobyr I, Offidani A. Botulinum toxin off-label use in dermatology: a review. Skin Appendage Disord. 2017 Mar;3(1):39-56.

60 González-Ramos J, Sendagorta-Cudós E, González-López G, Mayor-Ibarguren A, Feltes-Ochoa R, Herranz-Pinto P. Efficacy of botulinum toxin in pachyonychia congenita type 1: report of two new cases: efficacy of botulinum toxin in pachyonychia congenita type 1 . Dermatol Ther. 2016 Jan;29(1):32-6.

61 Pan B, Schröder W, Jostock R, Schwartz M, Rosson G, Polydefkis M. Nociceptin/orphanin FQ opioid peptide-receptor expression in pachyonychia congenita. J Peripher Nerv Syst. 2018 Dec;23(4):241-8.

62 Teng JMC, Bartholomew FB, Patel V, Sun G. Novel treatment of painful plantar keratoder$\mathrm{ma}$ in pachyonychia congenita using topical sirolimus. Clin Exp Dermatol. 2018 Dec; 43(8):968-71.
63 Abdollahimajd F, Rajabi F, Shahidi-Dadras M, Saket S, Youssefian L, Vahidnezhad H, et al. Pachyonychia congenita: a case report of a successful treatment with rosuvastatin in a patient with a KRT6A mutation. Br J Dermatol. 2019 Sep;181(3):584-6.

64 El-Darouti MA, Marzouk SA, Nabil N, AbdelHalim MRE, El-Komy MHM, Abdel-Latif M. Pachyonychia congenita: treatment of the thickened nails and palmoplantar circumscribed callosities with urea $40 \%$ paste. J Eur Acad Dermatol Venereol. 2006;20(5):615-7.

65 Smith FJ, Hansen CD, Hull PR, Kaspar RL, McLean WI, O'Toole E, et al. Pachyonychia congenita. In: Adam MP, Ardinger $\mathrm{HH}$, Pagon RA, Wallace SE, Bean LJ, Stephens K, et al., editors. GeneReviews ${ }^{\circ}$. University of Washington, Seattle; 1993. 